\title{
The Operation Mechanism of Emission Right Trading and Analysis on the Operation Effect
}

\author{
Ding Shanshan ${ }^{1} \&$ Duan Jindong ${ }^{2}$ \\ ${ }^{1}$ Graduate of Economics and Management College, Nanjing University of Aeronautics and Astronautics, \\ Nanjing, China \\ ${ }^{2}$ Professor of Economics and Management College, Nanjing University of Aeronautics and Astronautics, \\ Nanjing, China \\ Correspondence: Ding Shanshan, College of Economics and Management, Nanjing University of Aeronautics \\ and Astronautics, Nanjing, 210000, China. Tel: 158-5183-8705. E-mail: 2401151250@qq.com
}

Received: December 11, 2016

Accepted: December 24, 2016

Online Published: January 10, 2017

doi:10.5539/ijef.v9n2p150

URL: http://dx.doi.org/10.5539/ijef.v9n2p150

\begin{abstract}
The current environment pollution problem is becoming increasingly serious in the world, many solutions are being explored. Emission right trading as a means which can promote economic development and protect the ecological environment has attracted more and more attention of international society. With China's increasing emphasis on environmental governance problem, it is important to be familiar with emission right trading and the general operation mechanism. Referring to the successful operation experience of the developed countries such as the United States, undoubtedly has important effect on promoting China's relevant management departments and enterprises in energy-saving emission reduction work.
\end{abstract}

Keywords: emission rights trading, analysis on the effect, operation mechanism

\section{Introduction}

The current situation of global environmental problem becomes more and more serious, especially the waste water, waste gas and waste (commonly known as the "three wastes") pollution. In order to better solve the problem of environmental pollution and as for the impact on industrial production and economic development, western countries put forward the theory of emission rights trading early in the 20th century 60 years and in 1977 the United States took the lead in the implementation of emissions rights trading system. Since then, emission rights' trading has promoted the environmental governance in the relevant countries.

Our country in recent years is full implementing the system, but many aspects of emission rights trading in our country is still a blank. It is imperative to learn from the successful experience of developed countries and finally to find out the most suitable system for China's emissions rights trading.

\section{Emission Right Trading and Its Operation Mechanism}

Emission trading is a positive economic trading based on the market, the government firstly determines the jurisdiction of the environmental quality objectives, and establishes a legal compliance of sewage in the sewage line according to a certain proportion of emission rights, then uses a variety of ways to make the enterprise get normal amount of sewage so as to change the government's mandatory requirements to the enterprise consciousness management. The biggest advantage is the high efficiency of controlling environmental pollution. Specifically, the main responsibilities of environmental supervision and management departments is to determine the jurisdiction of quality objectives of regional environment, and enterprises pollution control objectives turns into enterprises decision matters. That is to say, in the emission rights trading market, the enterprise could independently decide to buy or sell the emission rights according to its own situation.

\subsection{The Principle of Emission Rights Trading}

The connotation of Emission rights trading explicitly requires enterprises freely to choose to buy or sell emission rights trading according to their own capacity of controlling pollution in the emissions trading market and to achieve the optimal allocation of resources. The motivation of this operation is the different abilities, levels as well as costs for corporate to fight against pollution. For some enterprises with low cost of controlling pollution can obtain compensation through the sale of emission rights. And those enterprise with high cost of controlling 
pollution, as long as the price of purchasing emission rights is lower than the cost of controlling pollution, these enterprises can spend less money to achieve the goal of pollution control, under the premise of paying a certain price for its pollution emission, in order to protect the ecological environment with relatively lower costs compared with controlling pollution by themselves, and finally to achieve a win-win situation.

\subsection{Determination of the Optimal Level of Pollution Emission Is the Fundamental of Emission Rights Trading}

The principle of emissions trading is based on the price and quantity of optimal emission rights, and achieving optimal allocation of social resources under the premise of free market.

Optimal emission quantity is also called optimal pollution level $\mathrm{Q}^{*}$, it is determined by the marginal private net income MNPB (consumers obtain an extra unit of satisfaction degree through the increase of goods or services consumption) and marginal external cost MEC (due to an extra unit of a product yield increase the third persons' cost). There is inverse relationship between Marginal private net income MNPB and production scale, MNPB reducing with the expansion of the scale of production; There is positive relationship between marginal external cost MEC and the scale of production, MEC increasing with the scale of production, the relationship between both of them and the scale of production can be seen by the following figure. As shown in the figure, the area underneath the line MNPB is the total revenue and the area underneath line MEC is the total cost. When the marginal private net income MNPB is equal to the marginal external cost MEC, the difference between the total revenue and total cost is maximum, at this time, the pollution level of $\mathrm{Q}^{*}$ determined by the horizontal axis is the optimal pollution level, under the optimal level of pollution, net contribution is maximum.

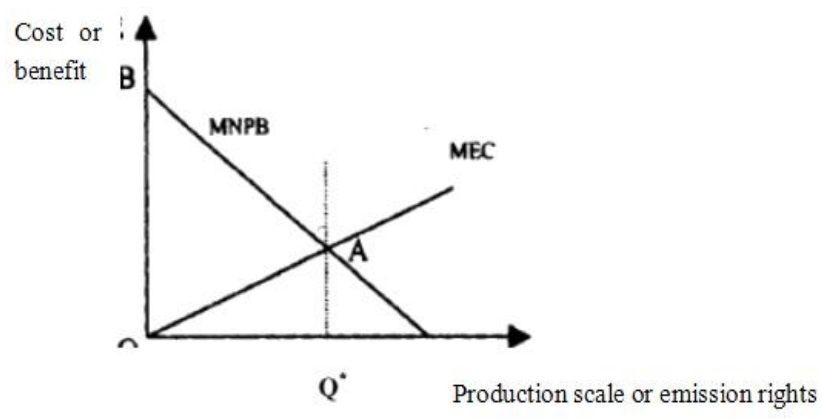

Figure 1. How to determine the optimal discharge level

\subsection{The Core of the Government Management Is to Determine the Legal Emission Rights}

The basis of government environmental supervision and management department to identify legal compliance emission rights and issuing emission rights licenses is the optimal pollution level $\mathrm{Q}^{*}$. Issuing emission rights license is regulated by government, obviously, the purpose of the government issuing emission rights license is to protect the ecological environment without intended profit, so the total supply curve of emission rights in the figure below is perpendicular to the horizontal axis line, it doesn't change with the price change. The $\mathrm{p}^{*}$ on the vertical axis indicates the government charging when issuing every unit of emission permits to enterprises. So, for the enterprises which need to discharge waste, they need to make choices between buying emission rights and governing pollution by themselves. Sewage Demand of emission rights for these enterprises is determined by the marginal cost of fighting against pollution, so the marginal cost curve MAC can be seen as the total demand curve of emission rights. According to the supply theory, the market price of emission rights is decided by the total demand of emission rights MAC and the total supply $\mathrm{S}$, the optimal price of emission rights is just the price determined by MNPB. When MAC (D1) $>$ MNPB, then the price of emission rights $\mathrm{P} 1>\mathrm{P}^{*}$. At this time, the costs of enterprises fighting pollution on their own are too high, enterprises will choose to buy emission rights; on the contrary, when the MAC (D2) $<\mathrm{MNPB}$. At this time, the price of emission rights $\mathrm{P} 2<\mathrm{P} *$. Obviously, enterprises will choose to fight against pollution by themselves with lower cost, and then sell the remaining emission rights in the emission rights trading market so as to realize the maximization of personal income. This can greatly improve the consciousness of enterprises to reduce pollution and to protect ecological environment. 
Cost or benefit

or price

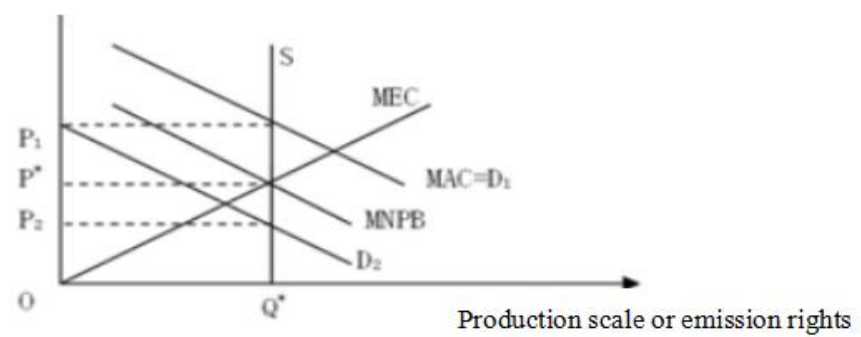

Figure 2. Principle and transaction process of emission trading

In short, environmental resource capacity (the capacity of natural ecological environment containing and digesting pollution) is regarded as a trading goods placed in the market. The perfection of the market mechanism will solve the external environment problem which has been troubled the government and the enterprise. Obviously, the emission rights trading will significantly reduce the administrative costs of the government to control and treat environmental pollution, and emission rights trading market is full of flexibility. Government as the unit of controlling the issue of emission rights licenses, the supply curve of emission rights licenses is controlled by the number of emission rights licenses issued by the government, and it can move with the change of emission rights licenses issued by the government. At the same time, the demand curve will move with the exit of older firms and the join of new enterprises. As is shown below.

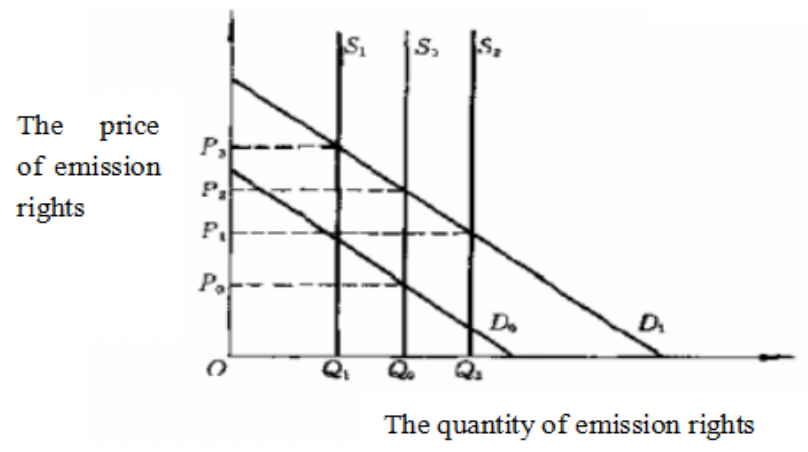

Figure 3. The change of the supply and demand of emission rights

As we can see in the figure above, when the government expands the number of emission rights licenses issued, the license number increases from Q0 to Q2, with the supply curve shifted to the right from S0 to S2, with the demand curve unchanged, the equilibrium price for emission rights decreases; on the contrary, when the government reduces the issuance of emission rights licenses, that is to say the number of licenses decreases from Q0 to Q1, at this time, the supply curve shifts from S0 to S1 to the left, if the present demand curve doesn't change, then the equilibrium price of emission rights will rise. If in the circumstance that the supply curve unchanged, the join of new enterprises will cause the increase of demand, the demand curve shifts from D0 to D1 to the right, eventually price of emission rights rises. This operation mechanism will eliminate enterprises with large amount of pollution as well as high costs for pollution control, which is advantageous to achieve the optimal allocation of resources.

\section{Analysis of the Mode of American Emission Right Trading}

After years of practice, American emission right trading has formed three different transaction modes which are very important for the effectiveness and efficiency of the emission right trading. The three emission right trading patterns are respectively total amount-transaction mode, non continuous cutting pollutant emission mode and standard-credit mode.

\subsection{Total Amount-Transaction Mode}

Many U.S. environmental protection plan use total amount-transaction mode such as grading reducing lead plan, grading reducing CFC program, the acid rain program and regional clean air incentive market plan. Due to different pollutants, total amount-transaction mode can be divided into "production permit total 
amount-transaction" and "emission permit total amount-transaction"."production permit total amount-transaction" specific point to producers produced products causing pollution in the use process, the issuing emission permits in this mode means hidden pollution load which is allowed to be contained in products. Relatively, "emission permit total amount-transaction" points to producers produced products causing pollution in the production process, the permit is for the emissions of pollutants produced in the production. Total amount-transaction mode is conducting emission credit transaction according to the total amount of pollutants. Environmental protection supervision department first assesses the environmental quality of a region, obtains the environmental carrying capacity of the region, so as to get the total amount of emission rights within the region, then divides the emission rights into the same parts, and distributes to the enterprises in need making emission rights disperse to the whole society. At that time, the emission right trading system was not perfect, enterprises need to make a deal by full-time agents who are responsible for the coordination between the buyers and sellers. Different subjects can purchase or sell emission rights with information on the supply and demand right in this way. In addition, the enterprises can also buy emission rights through the annual auction.

\subsection{Non Continuous Cutting Pollutant Emission Mode}

The highlighting characteristic of non-continuous cutting pollutant emission mode is non continuous which means the enterprise can get emission credit continuous emission reduction on many occasions in a period of time. After all, it's very hard to achieve continuous emission reduction in a continuous time owing to many affecting factors, such as economic conditions, weather and production cycle. But noncontiguous emission reduction on many occasions is relatively easy for the enterprise which means they can make their own to avoid adverse external factors interference in order to achieve emission reduction. In this way, requirement for enterprises to obtain emission credit is greatly reduced, not only can stimulate initiative of enterprises, but also make emission reduction standards more flexible. What's more, the environmental protection supervision department will be easier to implement this system. With less restrictions of this mode, it can no doubt reduce the burden of the work of the relevant departments, thereby reduce management costs and save management time.

\subsection{Standard-Credit Mode}

The last but not least is standard-credit mode which was first applied to the state atmosphere "emission trading scheme" proposed the United States Environmental Protection Agency. An example is given to illustrate the operation of this mode. For example, the government environmental protection supervision departments sets that under a year, total emissions sulfur dioxide from thermal power enterprises should be no more than 40 million tons, A power plant in the year up to now has discharged sulfur dioxide 10 million tons, and has been devoted to emission reduction in the remaining time of the year. Now a power plant has the right to apply for emission credit from the environmental protection supervision department which is exactly the difference of 40 million tons set by the government environmental protection supervision department and 10 million tons discharged by a power plant. In this mode, there are many needs to meet in order to obtain credit, such as emission behavior must occur within a continuous period of time, different from non continuous cutting pollutant emission mode which can be segmented several times and also the emissions of pollutants must be quantified and recognized by the public. In a word, it is the pattern to apply most early in practice with the most restricts.

\section{The Choice of Operation Mode and Effect Prediction of Emission Right Trading System in China}

The pilot of China's emission right trading is in a relatively short time without wide range of implementation. The practice has encountered many theoretical and practical problems which need to be solved, but the Chinese government has determined to launch the national carbon emission right trading in 2017 which need us to determine the carbon emission right trading patterns suitable for the situation of the present China.

\subsection{The Choice of the Emission Right Trading Mode for Our Country}

Total amount-transaction mode is used in the United States most frequently, on the contrary, non continuous cutting pollutant emission mode is used seldom. The reason for this phenomenon is that Total amount-transaction mode has higher market liquidity and participation than the other two modes, and also it has low transaction costs. In accordance with China's current situation, emission right trading is a brand new system without too much practical experience and needs all transactions subjects to increase market activity, and needs to control the transaction costs in a moderate level, then we are supposed to think of a way to reduce the management costs of relevant departments. Obviously, Total amount-transaction mode fully meets all the needs of China's emission right trading market, so the suitable mode for China's emission right trading market is the Total amount-transaction mode.

Moreover, there are wide varieties of transactions subjects in the American emission right trading market which 
can be divided into three categories: standards, investors and environmentalists. It's the same to Germany's participation subjects in emission right trading market. The diversification of the main body of the transaction can help to satisfy different purpose of transactions. At the same time, it can vigorously promote emissions trading. China should draw lessons from the experience of foreign emission right trading system, increase the diversification of the attending subjects of the emission right trading in order to attract investors, speculators and environmentalists to enter the trading so as to increase transaction subject categories and improve level of trading activity.

Furthermore, there are large number of brokerage firms, consulting institutions and auction companies and other intermediaries as a bridge and link trading in the American emission right trading. Brokerage company plays a role of agent which is responsible for the buy and sell work of emission rights attached to provide price information for the parties of the transaction. The role of a consulting institution is to provide price and relevant information for the traders for reference under its own understanding on the trading market. The work of auction company is to sell emission rights obtained from enterprises or government departments for auction. Obviously, these intermediaries improve the emission right trading market and increase the level of activity in the market. Traders can get information through intermediaries and save many expenses, including searching for information cost and cost of buying procedures. All in all, the role of intermediaries is very important which means China's emission right trading market should also attach importance to the important role of intermediaries and encourage the establishment of relevant emission right trading intermediaries so as to lay the foundation for the development of emission right trading .

\subsection{The Evaluation of Operation Effect of the Emission Right Transaction--Based on the Case of Electric Power Industry}

Based on rich coal resource reserves in China, the electricity enterprise in our country mainly rely on coal-fired power to provide the required energy, while the proportion of renewable energy is not large. The amount of sulfur dioxide generated by coal combustion accounts for more than $80 \%$ of China's total emissions of sulfur dioxide, amount of sulfur dioxide from power plants burning coal accounts for more than $40 \%$ of China's total emissions of sulfur dioxide. That is to say, the power industry is one of the main sources of emissions of sulfur dioxide, but obviously the number of power generation enterprises in China will not reduce, nothing could prevent the expansion of power generation enterprises, so the control of emissions of sulfur dioxide of power industry is crucial.

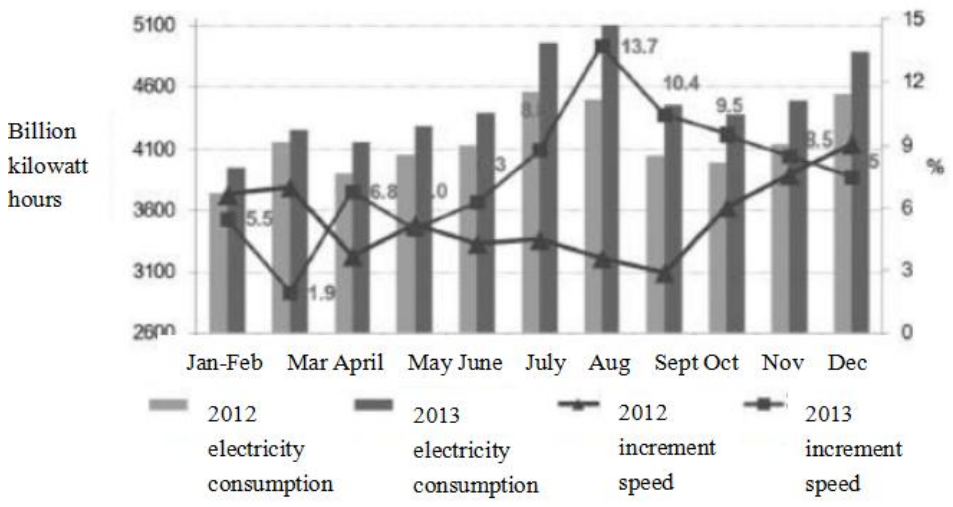

Figure 4. 2012 to 2013 the electricity consumption of the whole society and the growth rate of statistics

We Can see in Figure 4, the electricity consumption of the whole society has increased and with the continued development of the economy, it will have been showing a rising trend, apparently in China power industry in recent years and even decades will has been in growth ,reducing the number of power generation enterprises is clearly not realistic, then the control of emissions of sulfur dioxide of power industry becomes the most important to control the air pollution. 
Table 1. The proportion of thermal power in gross generating capacity from 2002 to 2015 in China

\begin{tabular}{lc}
\hline Year & Proportion \\
\hline 2015 & 73.1 \\
2014 & 74.9 \\
2013 & 80.4 \\
2012 & 78.6 \\
2011 & 82.8 \\
2010 & 80.3 \\
2009 & 81.7 \\
2008 & 81.8 \\
2007 & 84.2 \\
2006 & 82.4 \\
2005 & 81.6 \\
2004 & 82.6 \\
2003 & 82.3 \\
2002 & 81.7 \\
2001 & 81.2 \\
\hline
\end{tabular}

From the table above, we can see thermal power occupies an important position in gross generating capacity in our country. Next I will compare the difference between implementing or not implementing the emission right trading through intuitive calculation result according to the data of sulfur dioxide emissions in China, and focus on the analysis of the difference between the cost of implementing or not implementing the emission right trading, and also put forward some opinions and suggestions for the development of emission right trading.

If Electric power enterprises do not implement the emissions trading system, they must use the coal desulfurization process. The cost of desulfurization treatment includes the purchase of equipment and the equipment running cost. The table below counts the amount and cost of emissions of sulfur dioxide of China's electric power industry, the data of Year 2015 in the table is estimated according to < China electric power market analysis and research >:

Table 2. Statistics of sulfur dioxide emissions and cost in China's electric power industry

\begin{tabular}{cccccc}
\hline Year & $\begin{array}{c}\text { Sulfur dioxide } \\
\text { emissions (Million ton) }\end{array}$ & $\begin{array}{c}\text { Target of Sulfur } \\
\text { dioxide emission } \\
\text { control (Million ton) }\end{array}$ & $\begin{array}{c}\text { Desulfurization } \\
\text { investment cost } \\
\text { (Million yuan) }\end{array}$ & $\begin{array}{c}\text { Desulfurization process } \\
\text { operating cost (Million } \\
\text { yuan) }\end{array}$ & $\begin{array}{c}\text { Payment for Sulfur dioxide } \\
\text { emissions(Million yuan) }\end{array}$ \\
\hline 2011 & 1706 & 851 & 1013245 & 855000 & 538683 \\
2012 & 1757 & 808 & 1014367 & 949000 & 511464 \\
2013 & 1810 & 767 & 1117680 & 1043000 & 485511 \\
2014 & 1864 & 729 & 1176807 & 1135000 & 461457 \\
2015 & 1920 & 693 & 1178098 & 1227000 & 438669 \\
2016 & 1968 & 658 & 1104675 & 1310000 & 416514 \\
2017 & 2017 & 625 & 1257654 & 1392000 & 395625 \\
2018 & 2067 & 594 & 1379009 & 1473000 & 376002 \\
2019 & 2119 & 570 & 1490987 & 1549000 & 360810 \\
2020 & 2160 & 550 & 1528752 & 1610000 & 348150 \\
2021 & 2205 & 523 & 1539630 & 1652000 & 324768 \\
2022 & 2273 & 517 & 1570215 & 1694000 & 309421 \\
2023 & 2324 & 506 & 1621734 & 1720000 & 288360 \\
2024 & 2395 & 484 & 1679032 & 1751000 & 263945 \\
2025 & 2430 & 462 & 1745953 & 1784000 & 241753 \\
合计 & 31015 & 9337 & 20417838 & 21144000 & 5761132 \\
\hline
\end{tabular}

According to the table above, total Desulfurization cost $=$ investment cost + operation cost $=41561838$ million yuan approximately equal to 4156 billion yuan. By comparison, excessive emissions of sulfur dioxide should be payed 5761132 million yuan, approximately equal to 576 billion yuan.

At this time, enterprises can choose to buy emission rights for excessive emission of sulfur dioxide, emission rights pricing has become the key of the problem. In order that the market can produce enough demand and 
supply, the minimum of emission rights pricing must be less than the worst level of social handling pollution cost which is the biggest cost of pollution control for those enterprises with lag technology so as to satisfy the emission right requirements, also the maximum of emission rights pricing must be higher than the optimal social cost of pollution control which is the least cost of pollution treatment for those enterprise with advanced technology so as to ensure the supply of emission rights.

The Shanghai municipal government has put forward a pricing formula based on water pollution:

$$
P=(2 A+5 B) * \lambda * C * D
$$

In the above formula, $\mathrm{P}$ is the price of emission rights, $\mathrm{A}$ is the investment for reducing a unit of certain types of pollutants, $\mathrm{B}$ is operation cost needed for the reduction of a unit of certain pollutants, $\mathrm{C}$ is the weight for pollution factor, $\mathrm{D}$ is the weight for the functional area, $\lambda$ is transaction cost coefficient.

Obviously we can see from the above equation, the main factors affecting the price of emission rights are the capital and the running costs of pollution control.

The pricing formula based on sulfur dioxide emission rights can be modeled on the above equation, main influencing factors which are the invested capital and running costs have existed, the ratio of investment capital and running costs is $2: 5$ or is $1: 2.5$, so the weight coefficient of investment costs based on sulfur dioxide is $1 /$ $(1+2.5)$ about to 0.285 , then the weight coefficient of running cost is $1-0.285=0.715$. The equation follows the mathematical formula of price $=$ cost $/$ number, also we can say it calculates the price of emission right according to a unit of sulfur dioxide. And also we should plus the condition of transaction costs which is never be zero, so that it conforms to the actual situation, the transaction costs can be the cost for sulfur dioxide emissions, the specific formula is as follows:

$$
P=(0.285 A+0.715 B) / Q+E / Q
$$

In the formula, $\mathrm{A}$ is the investment funds to reduce emissions of sulfur dioxide, $\mathrm{B}$ is the operating costs to reduce the sulfur dioxide emissions, $\mathrm{Q}$ is the amount of sulfur dioxide emissions, $\mathrm{E}$ is the cost for per unit of sulfur dioxide emissions. Substitute the types in the equation with numbers:

$$
P=(0.285 * 20417838+0.715 * 21144000) / 31015+5761132 / 31015=860.81
$$

Results shows that, the price based on sulfur dioxide emission rights is $\$ 860.81 /$ ton, then the total costs to reduce emissions of sulfur dioxide is (31015-9337)*861.81=1868.23 billion yuan. Obviously, the price is lower than the needed operation cost to run the desulfurization equipment or the charges required to pay for sulfur dioxide emissions over emissions standards, and if the enterprises have high level of capacity for pollution control, they can sell the residual sulfur dioxide emissions for profit. In this way, the implementation of emission right trading system can not only save the cost for the enterprises, but also provide the enterprises with power of improving the level of pollution control.

\section{Suggestions for the Implementation of Emission Right Trading in China}

In order to control greenhouse gas emissions and promote low-carbon development, the central government and the local government and even enterprises are collaboratively promoting the construction of the national carbon emission right trading market. As the executive organ of the state power, the government has a wide range of functions and powers, which has the power to make the rules of the emission right trading system, so the government and relevant department will be playing an important role of guidance and guarantee in the construction of emission right trading system.

Firstly, it is necessary to strengthen the propaganda of environmental protection and emission rights related knowledge. At this stage, our people's awareness of environmental protection is still to be strengthened. At this time, the government should take on the responsibility of the popularization of environmental protection knowledge and the relevant knowledge of emission rights. There are a lot of methods to strengthen propaganda, but the government needs to take corresponding measures. For example, for the ordinary people with relatively low cultural level, the government can take measures like community lecture, community questionnaire like quiz to intensify propaganda, and to improve the mass awareness of environmental protection, and to guide people how to really achieve environmental protection in daily life. For the masses with medium culture level, the government can choose to conduct propaganda in units of the enterprises, and at the same time, emphasize knowledge about emission right. This will make enterprise workers become the supervisors of emission right trading system.

The government needs to attach enough importance to the education about environmental protection and related knowledge about emission right in institutions of higher learning. After all, the possibility for personnel of 
institutions of higher learning to engage in cutting-edge technology in the future is larger. Strengthening the education about environmental protection for college students can influence students, and also urge students to make environmental protection as the topic of the thesis. It can not only educate students themselves, but also expand the influence of environmental protection through research.

Then selecting the suitable method of initial allocation ways of emission rights considering about China's national conditions is very important. In the 1990s, the United States put forward three kinds of initial distribution ways of emission right trading system which are auction, fixed price sale and free distribution in the $<$ Clean Air Act> amendment, and its initial distribution way is free distribution. Obviously, our country can not just copy the American experience. What we need is to choose a suitable initial distribution with a clear analysis of our country's condition. There is no monitoring and forecasting system about the capacity for the environment to bear the environment pollutants in our country. Then the prediction of the capacity for the environment to bear the environment pollutants must be lacking. In addition, emission right must be in short supply in the state with too many enterprises' demand for the emission right, which makes it becomes a scarce commodity with value, then the most suitable way of the initial allocation considering China's national condition is distribution with payment.

Next putting building the data system on the basis of total amount control on the agenda cannot be ignored. The premise of emission right trading system is total control, it provides the limit amount of pollutants within a certain area, so the core issue of emission right trading system is how to accurately measure the maximum value of pollutants that a region can accommodate. But now in China the data system based on the total amount control is still blank. Without the premise of implementation of emission right trading system, it will be impossible to carry out the system. Total amount control needs a large amount of statistics based on the capacity for the environment to bear the environment pollutants in need of a lot of supporting data which requires a great deal of time, manpower and material resources. At present, our country is not only lack of the related research institutions, but also lack of relevant databases, so to put building the data system on the basis of total amount control on the agenda is the top priority of our government.

Indeed, enterprises as the major participants of the emission right trading system are playing main responsibility in the various links and various aspects in the whole operating process of emission right trading. Only when enterprises really take the environmental protection as one of the goals of their own development, can they form the long-term and effective support force for environmental protection. Thus, improving the cognitive level of emission right trading system and environmental protection further is especially important. Even though, many enterprises have realized that extensive economic growth mode has been against with China's sustainable economic development policy, and they are aware of the importance of environmental protection. But for enterprises to actively participate in the emission right trading system with a fair attitude is not in place. The successful implement of the emission right trading system cannot be separated from the support and maintenance from enterprises as main participants as well as the active participating attitude of enterprises. When enterprises don't have enough emission right, they should choose to buy consciously the emission rights in the trading market; when they possess remaining emission rights, they ought to sell the emission rights in the market with the attitude of fairness as well as consciousness. It is prohibited to make a deal of emission rights in the black market and in disguise to improve emission rights prices on purpose or for "hoarding" mind to refuse to sell emission rights.

\section{Concluding Remarks}

According to China's current environmental situation and economic development situation, the implementation of emission right trading system is imperative, but absolutely can not directly copy the experience of developed countries, we must draw lessons from the successful experience and choose the most suitable implementation mechanism according to China's actual situation. The emission right trading system is still blank in China which is a good thing because it can completely start from zero without any other factors of interference, but also is not a good thing because it shows that our country has been lagging behind the western developed countries for decades in the implementation of emission right trading system. And now the government and enterprises must get together to strive to implement emission right trading system so as to catch up these developed countries.

\section{Acknowledgement}

This paper is supported in part by my advisor Duan Jindong. He has spared no effort to point out some parts of my paper in need of modification. Also he has spent a lot of time answering any question from me. I have to thank for his patience, hard work as well as his sense of responsibility.

Fund Project: Research on the pricing mechanism of emission rights under the specific regional environment 
(No. kfjj20160105). This work is supported by' Foundation of Graduate Innovation Center in NUAA ' and 'the Fundamental Research Funds for the Central Universities'.

\section{References}

Qiaoling, T. (2011). A brief discussion on the <American clean energy and Security Act> and its impact on emissions trading system. Financial Services Law Review, 1, 219-241.

Qunfei, D. (2015). The problems and Countermeasures of the current emission trading market mechanism. Ecological Economy, 1, 103-108.

Ren, R., \& Shuxun, Z. (2016). Research on the reform ideas of emission trading mechanism based on the total amount control. Environmental Science and Management, 3, 19-24.

Xiuyuan, X. (2014). The problems and solutions of emission trading in China. Pricing Theory and Practice, 8 , 58-60.

Zhengge, T., \& Renjun, C. (2015). Emissions trading mechanism in Chinese can realize the Potter effect? Economic Research, 7, 160-173.

Zhongquan, C., Yusen, X., \& Xinliang, Z. (2015). The role of emission trading mechanism for pollution control in industrial. Technology and Economy, 1, 82-88.

\section{Copyrights}

Copyright for this article is retained by the author(s), with first publication rights granted to the journal.

This is an open-access article distributed under the terms and conditions of the Creative Commons Attribution license (http://creativecommons.org/licenses/by/4.0/). 